\title{
HUBUNGAN DUKUNGAN SUAMI DENGAN PEMBERIAN ASI EKSKLUSIF DI DAERAH PERDESAAN
}

\author{
Association of Husband Support and Exclusive Breastfeeding in Rural Area \\ Novira Kusumayanti ${ }^{1}$, Triska Susila Nindya ${ }^{2}$ \\ ${ }^{1}$ Program Studi S1 Ilmu Gizi, Fakultas Kesehatan Masyarakat, Universitas Airlangga, Surabaya \\ ${ }^{2}$ Departemen Gizi Kesehatan, Fakultas Kesehatan Masyarakat, Universitas Airlangga, Surabaya \\ Email: kusumayanti_novira@yahoo.co.id
}

\begin{abstract}
ABSTRAK
Pemberian ASI eksklusif dapat mengurangi tingkat kematian bayi. Pemberian ASI eksklusif di Indonesia cakupannya masih sangat rendah. Banyak faktor yang mempengaruhi pemberian ASI eksklusif diantaranya adalah dukungan suami. Dukungan suami merupakan dukungan yang turut berperan menentukan keadaan emosi atau perasaan ibu sehingga mempengaruhi kelancaran reflek pengeluaran ASI. Penelitian ini bertujuan untuk mengetahui hubungan dukungan suami dengan pemberian ASI eksklusif di Kecamatan Kademangan Kabupaten Blitar. Penelitian ini menggunakan rancangan cross sectional. Wawancara dilakukan pada 66 ibu menyusui dengan bayi umur 6-12 bulan. Cara pengambilan sampel menggunakan simple random sampling. Lokasi penelitian di enam desa Kecamatan Kademangan Kabupaten Blitar dilakukan pada bulan Oktober 2016. Analisis statistik dilakukan secara bivariat dengan uji korelasi Spearman. Prevalensi pemberian ASI eksklusif sebesar 21,2\%. Sebagian besar suami mendukung pemberian ASI eksklusif (72,7\%). Berdasarkan uji tabulasi silang diketahui bahwa dukungan suami lebih besar peluangnya $(27,1 \%)$ terhadap pemberian ASI eksklusif dibandingkan suami yang tidak mendukung (5,6\%). Walaupun uji korelasi spearman menunjukkan tidak terdapat hubungan yang signifikan antara dukungan dengan pemberian ASI eksklusif. Ibu yang mendapat dukungan dari suami memiliki proporsi yang lebih besar memberi ASI eksklusif dibandingkan dengan yang tidak mendapatkan dukungan suami meskipun secara statistik tidak berhubungan secara signifikan.
\end{abstract}

Kata kunci: ASI eksklusif, dukungan suami, perdesaan

\begin{abstract}
Exclusive breastfeeding could decrease infant mortality. Exclusive breastfeeding coverage in Indonesia is still low. Many factors affect exclusive breastfeeding including husband support. Husband support contribute to maternal emotion that affect the smooth reflexes of breast milk production. This study aimed to determine the relationship of husband support and exclusive breastfeeding in the Kademangan district, Blitar. This is cross sectional study. Interview was done to 66 breastfeed mothers with infants aged 6-12 months. The sample was taken by simple random sampling. Location of this study was six villages in Kademangan district, Blitar and conducted in October 2016. Bivariate analysis was performed by Spearman correlation test. The prevalence of exclusive breastfeeding was 21.2\%. Most of husband support exclusive breastfeeding. Based on cross tabulation, mother who gave breastfeeding to their children was higher when they are supported by their husband. Eventhough Spearman correlation test showed no significant relationship between husband support and exclusive breastfeeding. Mothers who had support from their husband had a higher proportion of giving exclusive breastfeeding than had not supported by their husband, eventhough not statistically significant correlated.
\end{abstract}

Keywords: exclusive breastfeeding, husband support, rural area

\section{PENDAHULUAN}

Bayi yang mendapatkan ASI eksklusif merupakan bayi yang hanya menerima ASI saja sehingga tidak ada cairan atau padatan lainnya diberikan, bahkan air dengan pengecualian rehidrasi oral, atau tetes/sirup vitamin, mineral atau obat-obatan. ASI yang pertama kali keluar (kolostrum) mengandung zat kekebalan tubuh dari ibu yang dapat melindungi bayi dari berbagai penyakit yang dapat menyebabkan kematian bayi seperti diare, ISPA, dan radang paru-paru. Bayi 
yang diberi ASI memiliki risiko lebih rendah terkena penyakit degeneratif seperti penyakit darah tinggi, diabetes tipe 2, dan obesitas pada saat dewasa (WHO dan Unicef, 2003).

Pemberian ASI eksklusif di negara berkembang berhasil menyelamatkan sekitar 1,5 juta bayi/tahun. Atas dasar tersebut, World Health Organization (WHO) merekomendasikan Kepmenkes RI No. 450/Menkes/SK/ IV tahun 2004 untuk memberi ASI eksklusif sampai bayi berusia 6 bulan.

Pemberian ASI eksklusif di Indonesia cakupannya masih sangat rendah. Proporsi pemberian ASI saja (Eksklusif) menurut data Riskesdas 2013, pada bayi umur 0 bulan adalah $52,7 \%$, persentase ASI eksklusif semakin menurun dengan meningkatnya kelompok umur bayi. Pada bayi berumur 6 bulan yang menyusui eksklusif hanya sebesar $30,2 \%$. Tidak adanya dukungan keluarga dalam pemberian ASI eksklusif merupakan alasan yang banyak dikemukakan oleh ibu. Oleh karena itu, faktor dukungan keluarga (suami, orang tua) merupakan faktor penguat bagi ibu menyusui memberikan ASI eksklusif. Tidak hanya ibu saja yang bertanggung jawab terhadap suksesnya pemberian ASI, tetapi juga ayah, nenek, kakek, dan orang-orang yang akan terlibat dalam kepengurusan bayi nantinya (Roesli, 2008).

Dari survei yang dilaksanakan pada tahun 2002 oleh Nutrition \& Health Surveillance System (NSS) kerja sama dengan Balitbangkes dan Helen Keller International yang dilaksanakan di empat kota yaitu Jakarta, Surabaya, Semarang, Makasar dan dilaksanakan juga pada 8 perdesaan yang berada di Sumatra Barat, Lampung, Banten, Jawa Barat, Jawa Tengah, Jawa Timur, Nusa Tenggara Barat, Sulawesi Selatan menyatakan bahwa ibu yang menyusui ASI eksklusif pada bayi umur 4-5 bulan di perkotaan antara 14\%-21\%, sedangkan di perdesaan $14 \%-26 \%$. Pencapaian ASI eksklusif 5-6 bulan di perkotaan berkisar antara $3 \%-18 \%$ sedangkan di perdesaan $6 \%-19 \%$.

Suami/ayah memiliki peran yang sangat penting dalam keberhasilan menyusui adalah yaitu sebagai breastfeeding father. Breastfeeding father adalah peran suami dengan cara memberi dukungan kepada ibu menyusui akan mempengaruhi terhadap pemberian ASI eksklusif. Dukungan penuh seorang suami kepada istrinya dalam proses menyusui bayinya meningkatkan keberhasilan menyusui ASI secara eksklusif. Peran breastfeeding father menjadi hal yang wajib dilakukan oleh ayah agar mendukung pemberian ASI eksklusif, sehingga proses menyusui secara eksklusif oleh ibu dapat berjalan dengan sukses (Ariani, 2010). Menurut Roesli (2012), dukungan suami sangat diperlukan agar pemberian ASI eksklusif bisa tercapai. Oleh karena itu, penelitian ini bertujuan untuk menganalisis dukungan suami dan peluang pemberian ASI eksklusif oleh ibu di Kecamatan Kademangan Kabupaten Blitar.

\section{METODE}

Penelitian ini merupakan penelitian observasional analitik. Rancang bangun penelitian menggunakan rancangan cross sectional. Populasi pada penelitian ini adalah semua ibu menyusui yang memiliki bayi usia 6-12 bulan di Kecamatan Kademangan Kabupaten Blitar. Sampel diambil dengan cara simple random sampling. Besar sampel dihitung berdasarkan rumus Slovin dengan $\alpha=0,05$ dan power $80 \%$, sampel yang dibutuhkan dalam penelitian ini adalah sebesar 66 orang ibu yang mempunyai bayi umur 6-12 bulan di Kecamatan Kademangan Kabupaten Blitar.

Penelitian ini dilakukan di enam desa, Kecamatan Kademangan Kabupaten Blitar. Sebanyak enam desa dipilih dan ditentukan sebagai sampel daerah dengan dasar pertimbangan cakupan ASI eksklusif yang belum memenuhi target $60 \%$. Desa tersebut yaitu Desa Panggungduwet, Desa Kebonsari, Desa Bendosari, Desa Plumpungrejo, Desa Jimbe, Desa Kademangan. Pengambilan data dilakukan pada Bulan Oktober 2016.

Pada penelitian ini, variabel yang diteliti adalah karakteristik Ibu, dukungan suami, dan pemberian ASI eksklusif. Kriteria inklusi untuk sampel penelitian antara lain bayi merupakan kelahiran tunggal, ibu memiliki bayi yang tidak bibir sumbing. Informasi yang didapatkan untuk penelitian ini melalui wawancara kepada ibu menggunakan kuesioner.

Hubungan antara variabel bebas dengan variabel terikat dianalisis menggunakan uji 
korelasi Spearman dengan tingkat kemaknaan 0,05 . Penelitian ini telah lolos kaji etik oleh komite Etik Penelitian Kesehatan Fakultas Masyarakat Universitas Airlangga dengan nomor 568-KEPK.

\section{HASIL DAN PEMBAHASAN}

\section{Karakteristik Responden}

Berdasarkan Tabel 1 dapat diketahui bahwa sebagian besar ibu berumur 26-35 tahun dengan proporsi $60,6 \%$ dan sebagian kecil berumur $>35$ tahun dengan proporsi $9,1 \%$. Ibu yang berusia 19-35 tahun memiliki produksi ASI yang baik dan menghasilkan cukup ASI dibandingkan dengan berusia $>35$ tahun. Pada ibu primipara yang berumur $>35$ tahun, suplai jumlah ASI cenderung tidak cukup karena produksi ASI mengalami sedikit penurunan (Notoatmodjo, 2007)

Usia berhubungan dengan kondisi kematangan emosional seseorang dalam berpikir dan berperilaku, sehingga ibu dengan umur $>25$ tahun dan $<35$ tahun berpeluang memberikan ASI eksklusif (Nursalam, 2001). Pendidikan ibu sebagian besar tamat SMP dengan proporsi $48,5 \%$ dan hanya sedikit yang tamat Perguruan Tinggi $(6,0 \%)$.

Tabel 1. Distribusi Frekuensi Karakteristik Ibu

\begin{tabular}{lrr}
\hline \multicolumn{1}{c}{ Karakteristik Ibu } & $\mathbf{n}$ & $\mathbf{\%}$ \\
\hline Umur Ibu & & \\
19-25 tahun & 20 & 30,3 \\
26-35 tahun & 40 & 60,6 \\
>35 tahun & 6 & 9,1 \\
Pendidikan Ibu & & \\
Tidak Tamat SD & 0 & 0.0 \\
Tamat SD & 12 & 18,2 \\
Tamat SMP & 32 & 48,5 \\
Tamat SMA & 18 & 27,3 \\
Tamat PT & 4 & 6,0 \\
Pekerjaan Ibu & & \\
Bekerja & 7 & 10,6 \\
Tidak Bekerja & 59 & 89,4 \\
Paritas Ibu & & \\
Primipara & 19 & 28,7 \\
$\quad$ Multipara & 47 & 71,3 \\
Jenis Persalinan & & \\
$\quad$ Normal & 53 & 80,3 \\
Operasi & 13 & 19,7 \\
\hline
\end{tabular}

Semakin tinggi tingkat pendidikan yang didapat oleh ibu, semakin banyak ibu yang memberikan ASI eksklusif pada bayi umur 0-6 bulan (Notoatmodjo, 2007). Ibu yang menerima/memahami informasi dengan baik dan mempraktikannya maka akan berperilaku baik dan berpeluang dalam memberikan ASI eksklusif meskipun tingkat pendidikannya rendah (Febriyanti dan Ernawati, 2014).

Sebagian besar ibu tidak bekerja ataupun menjadi ibu rumah tangga $(89,4 \%)$, dan sebagian kecil ibu bekerja $(10,6 \%)$. Ibu yang tidak bekerja lebih banyak waktunya untuk merawat bayinya ataupun menyusui bayinya, tetapi pada ibu yang bekerja masih ada peluang untuk menyusui bayinya terutama dalam pemberian ASI secara Eksklusif. Hal ini diterapkan oleh responden yang bekerja dan tetap memberikan ASI eksklusif $(14,3 \%)$ yaitu dengan memberikan ASI perah pada bayinya saat ibu bekerja. Bayi disusui sebelum berangkat kerja dan pada siang hari ataupun jam istirahat ibu pulang sebentar untuk menyusui bayinya sampai kenyang, atau memberikan ASI yang sudah diperah ditempat kerja. Pada saat ibu sudah dirumah sesering mungkin bayi disusui dan banyak menyusui pada malam hari (Ariani, 2010).

Sebagian besar ibu multipara $(71,3 \%)$ dan sebagian kecil ibu primipara $(28,7 \%)$. Paritas yang semakin tinggi (anak $>1$ ) berpengaruh positif dan berpeluang terhadap pemberian ASI eksklusif (Mabud, dkk., 2014). Ibu yang primipara dan multipara lebih banyak waktu luang untuk datang ke fasilitas pusat kesehatan masyarakat untuk mendapatkan layanan dan informasi terkait pemberian ASI eksklusif sehingga dapat dipraktikkan dan mempengaruhi produksi ASI yang lebih banyak dan mencukupi kebutuhan bayi selama pemberian ASI eksklusif (Proverawati dan Rahmawati, 2010).

Jenis persalinan adalah saat ibu melakukan proses persalinan yang dibedakan menjadi dua yaitu normal dan operasi. Saat proses persalinan sebagian besar $80,3 \%$ ibu dengan cara normal dan sebagian kecil 19,7\% ibu dengan cara operasi. Penolong persalinan memiliki peran yang dominan terhadap keberhasilan pemberian menyusun dini dan pencegahan terhadap pemberian makanan 
prelakteal (Rahardjo dan Setyowati, 2006). Ibu yang mengalami persalinan normal dan operasi berpeluang memberikan ASI eksklusif. Oleh karena adanya dukungan petugas kesehatan yang memberikan praktik Inisiasi Menyusui Dini (IMD) dan rawat gabung memperbesar peluang terhadap pemberian ASI eksklusif. Pada ibu yang proses persalinan secara operasi bisa berpeluang juga terhadap pemberian ASI secara Eksklusif, maka dari itu adanya dukungan petugas tenaga kesehatan yang memberikan praktek Inisiasi Menyusui Dini (IMD) dan rawat gabung untuk tahap awal berdampak terhadap pemberian ASI eksklusif. Kondisi ini mengakibatkan keinginan ibu yang lebih besar untuk menyusui bayinya (Agam, dkk., 2009).

\section{Pemberian ASI eksklusif}

Pemberian Air Susu Ibu (ASI) Eksklusif adalah pemberian tanpa makanan tambahan lain pada bayi umur 0-6 bulan dan hanya diberi ASI saja. Bayi tidak diberikan makanan/minuman lainnya kecuali yang langsung diproduksi oleh ibu karena bayi memperoleh nutrisi terbaiknya melalui ASI (Yuliarti, 2010).

Tabel 2. Distribusi Frekuensi Pemberian ASI Eksklusif 0-6 Bulan pada Bayi

\begin{tabular}{lcc}
\hline ASI eksklusif & $\mathbf{n}$ & $\mathbf{\%}$ \\
\hline Ya & 14 & 21,2 \\
Tidak & 52 & 78,8 \\
\hline
\end{tabular}

Berdasarkan Tabel 2 diatas, sebagian besar $(78,8 \%)$ ibu tidak memberikan ASI eksklusif dan hanya sebagian kecil $(21,2 \%)$ memberikan ASI eksklusif. Departemen Kesehatan Republik Indonesia melalui SK Menkes No. 450/Men.Kes/ SK/IV/2004 merekomendasikan pemberian ASI eksklusif yaitu hanya memberi ASI saja secara Eksklusif pada bayi berusia 0 sampai 6 bulan dan menetapkan target pemberian ASI eksklusif 6 bulan sebesar $80 \%$. Hasil studi ini sejalan dengan hasil SDKI tahun 2012 yang menunjukkan bahwa cakupan ASI eksklusif di Indonesia pada bayi di bawah umur 4 bulan hanya sebesar $42 \%$, tetapi pada umur 4-5 bulan ASI eksklusif menurun dengan prevalensi 27\%. 7 diantara 10 ibu merasa pemberian ASI saja tidak cukup untuk memenuhi kebutuhan gizi bayi sehingga bayi sudah menerima makanan tambahan (44\%), air putih (8\%), susu atau cairan tambahan lainnya $(8 \%)$ sebagai tambahan dari ASI atau sepenuhnya sudah disapih $(13 \%)$.

ASI eksklusif dianjurkan pada beberapa bulan pertama kehidupan karena ASI tidak terkontaminasi dan mengandung banyak gizi yang diperlukan anak pada umur tersebut. Pengenalan dini makanan yang rendah energi dan zat gizi lain atau yang disiapkan dalam kondisi tidak higienis dapat menyebabkan anak mengalami kurang gizi dan terinfeksi sehingga mempunyai daya tahan tubuh yang rendah terhadap penyakit (Kemenkes RI, 2013).

Tabel 3. Distribusi Frekuensi Dukungan Suami dalam Pemberian ASI Eksklusif

\begin{tabular}{lcc}
\hline Dukungan Suami & n & \% \\
\hline Mendukung & 48 & 72,7 \\
Tidak mendukung & 18 & 27,3 \\
\hline
\end{tabular}

\section{Hubungan Karakteristik Ibu dan Dukungan Suami terhadap ASI eksklusif}

Dukungan suami adalah peran aktif dalam merawat bayinya untuk menunjang program pemberian ASI eksklusif. Tabel 3 di atas menunjukkan sebagian besar $(72,7 \%)$ suami mendukung dalam pemberian ASI eksklusif.

Hasil penelitian menunjukkan bahwa sebanyak $22,5 \%$ ibu yang berusia $26-35$ tahun memberikan ASI eksklusif, sedangkan ibu yang berusia $>35$ tahun hanya sebagian kecil $(16,7 \%)$ memberikan ASI eksklusif. Hasil uji korelasi menunjukkan bahwa tidak terdapat hubungan antara usia ibu dengan pemberian ASI eksklusif dengan nilai $\mathrm{p}=0,986$. Hasil penelitian ini sesuai dengan penelitian Mabud, dkk. (2014) yang juga menunjukkan bahwa tidak ada hubungan usia ibu dengan pemberian ASI eksklusif.

Hasil studi ini berbeda dengan hasil penelitian Ibrahim (2000) yang menyatakan bahwa terdapat hubungan yang bermakna antara umur ibu dengan pemberian ASI eksklusif. Menurut Notoatmodjo (2005), umur merupakan faktor predisposisi yang mendorong individu untuk berperilaku. 
Produksi ASI ibu yang berusia 19-23 tahun lebih baik dibandingkan dengan berusia lebih tua. Primipara yang lebih dari 35 tahun cenderung tidak menghasilkan jumlah ASI yang cukup.

Tabel 4. Hubungan Karakteristik Ibu dengan Pemberian ASI Eksklusif

\begin{tabular}{|c|c|c|c|c|c|}
\hline \multirow{3}{*}{$\begin{array}{c}\text { Karakteristik } \\
\text { Ibu }\end{array}$} & \multicolumn{4}{|c|}{ ASI Eksklusif } & \multirow{3}{*}{$\mathbf{p}$} \\
\hline & \multicolumn{2}{|c|}{ Ya } & \multicolumn{2}{|c|}{ Tidak } & \\
\hline & $\mathbf{n}$ & $\%$ & $\mathbf{n}$ & $\%$ & \\
\hline \multicolumn{6}{|l|}{ Umur Ibu } \\
\hline 19-25 tahun & 4 & 20,0 & 16 & 80,0 & \multirow{3}{*}{0,986} \\
\hline 26-35 tahun & 9 & 22,5 & 31 & 77,5 & \\
\hline$>35$ tahun & 1 & 16,75 & 5 & 83,3 & \\
\hline \multicolumn{6}{|l|}{ Pendidikan Ibu } \\
\hline Tamat SD & 1 & 8,3 & 11 & 91,7 & \multirow{4}{*}{0,581} \\
\hline Tamat SMP & 8 & 25,0 & 24 & 75,0 & \\
\hline Tamat SMA & 5 & 27,8 & 13 & 72,2 & \\
\hline $\begin{array}{l}\text { Tamat } \\
\text { Akademik/PT }\end{array}$ & 0 & 0 & 4 & 100 & \\
\hline \multicolumn{6}{|l|}{ Pekerjaan Ibu } \\
\hline Bekerja & 1 & 14,3 & 6 & 85,7 & \multirow{2}{*}{0,642} \\
\hline Tidak Bekerja & 13 & 22,0 & 46 & 78,0 & \\
\hline \multicolumn{6}{|l|}{ Paritas } \\
\hline Primipara & 2 & 10,5 & 17 & 89,5 & \multirow{2}{*}{0,089} \\
\hline Multipara & 12 & 25,5 & 35 & 74,5 & \\
\hline \multicolumn{6}{|l|}{ Jenis Persalinan } \\
\hline Normal & 13 & 24,5 & 40 & 75,5 & \multirow[b]{2}{*}{0,189} \\
\hline Operasi & 1 & 7,7 & 12 & 92,3 & \\
\hline
\end{tabular}

Tidak adanya hubungan usia dengan pemberian ASI eksklusif dikarenakan usia bukan merupakan faktor yang langsung mempengaruhi perilaku pemberian ASI. Usia berhubungan dengan kondisi kematangan emosional seseorang dalam berpikir dan berperilaku (Nursalam, 2001). Sedangkan perilaku seseorang dipengaruhi oleh beberapa faktor lain seperti pendidikan, pekerjaan, paritas, jenis persalinan, budaya, layanan kesehatan, dan dukungan suami/keluarga (Notoadmodjo, 2003).

Berdasarkan hasil penelitian, ibu dengan tingkat pendidikan SMA memiliki persentase yang lebih besar $(27,8 \%)$ dalam memberikan ASI eksklusif, dibandingkan ibu yang berpendidikan akademik/PT. Hasil uji korelasi menunjukkan bahwa tidak terdapat hubungan antara pendidikan dengan pemberian ASI eksklusif dengan nilai $\mathrm{p}=0,581$. Hasil penelitian ini sesuai dengan penelitian Febriyanti dan Ernawati (2014) yang juga menunjukkan bahwa tidak ada hubungan pendidikan ibu dengan pemberian ASI eksklusif.

Menurut Depkes (2001), semakin tinggi tingkat pendidikan ibu, semakin banyak jumlah ibu yang memberikan ASI eksklusif pada bayinya. Pendidikan mempengaruhi proses belajar, makin tinggi pendidikan seseorang semakin mudah orang tersebut mendapatkan informasi. Pendidikan sangat erat kaitannya dengan pengetahuan. Seseorang dengan pendidikan tinggi, akan semakin luas pula pengetahuannya (Notoadmodjo, 2007). Pada hasil penelitian sebelumnya yang dilakukan Febriyanti dan Ernawati (2014) menunjukkan bahwa meskipun pendidikan ibu cukup baik namun jika ibu tidak menerima informasi ataupun memahami informasi yang didapat dan tidak punya keinginan untuk mempraktikannya maka akan tetap berperilaku sama.

Ibu yang tidak bekerja memiliki persentase yang lebih besar (22\%) dalam memberikan ASI eksklusif, dibandingkan ibu yang bekerja. Penelitian sebelumnya yang dilakukan oleh Febriyanti dan Ernawati (2014) menyatakan bahwa terdapat hubungan bermakna antara status pekerjaan ibu dengan pemberian ASI eksklusif. Ibu yang bekerja mempunyai risiko 4 kali untuk menghentikan pemberian ASI eksklusif dibandingkan dengan yang tidak bekerja.

Ibu yang tidak bekerja memiliki peluang yang lebih besar untuk memberikan ASI eksklusif, karena lebih fokus waktunya untuk merawat dan menyusui bayinya dibandingkan ibu yang bekerja. Ibu yang bekerja bisa tetap memberikan ASI eksklusif kepada bayinya selama 6 bulan, dan tidak memerlukan tambahan waktu setelah memperoleh cuti hamil 3 bulan. Ibu yang bekerja dapat memberikan ASI eksklusif kepada bayinya dengan cara memeras ASI, dan memberikannya kepada bayi saat ibu bekerja. Kunci sukses memberikan ASI secara Eksklusif adalah ibu dan keluarga mempunyai manajemen ASI yang baik. Manajemen ASI yang baik adalah ibu yang mengetahui cara memerah ASI ibu dan keluarga dapat saling mendukung, ibu dapat menyiapkan diri dan lingkungannya sebelum ibu kembali 
bekerja (Roesli, 2008). Dengan manajemen ASI yang baik responden yang bekerja dapat tetap memberikan ASI eksklusif (14,3\%) yaitu dengan memberikan ASI perah pada bayinya saat ibu bekerja. Bayi disusui sebelum berangkat kerja, siang hari ataupun saat jam istirahat ibu pulang sebentar untuk menyusui bayinya, selain itu bisa memberikan ASI yang sudah diperah di tempat kerja.

Hasil uji korelasi menunjukkan tidak terdapat hubungan antara pekerjaan ibu dengan pemberian ASI eksklusif dengan nilai $p=0,642$. Hasil penelitian ini sesuai dengan penelitian sebelumnya yang dilakukan oleh Ahmad (2014) di Puskesmas Pamotan, Semarang, bahwa pekerjaan tidak mempengaruhi pemberian ASI.

Pada penelitian ini, pekerjaan ibu tidak berhubungan dengan pemberian ASI eksklusif, namun beberapa cara yang dapat dianjurkan pada ibu yang bekerja yaitu susui bayi sebelum bekerja, ASI dikeluarkan untuk persediaan di rumah sebelum berangkat bekerja, ASI dapat disimpan di lemari pendingin dan dapat diberikan pada bayi dengan menggunakan cangkir pada saat ibu bekerja. Pada saat ibu sudah di rumah sesering mungkin bayi disusui dan jadwal menyusui bisa diperbanyak menyusui di malam hari. Ibu harus lebih banyak mengonsumsi minuman/ makanan yang bergizi selama bekerja dan menyusui, sehingga dapat mencapai keberhasilan dalam memberikan ASI eksklusif (Arini, 2012). Para petugas kesehatan sebaiknya memberikan informasi mengenai cara-cara yang dapat dilakukan agar ibu tetap dapat memberikan ASI meskipun ibu bekerja. Dengan pengetahuan yang benar, perlengkapan memerah ASI, dan dukungan dari tempat kerja maka ibu bekerja dapat memberikan ASI secara eksklusif (Roesli, 2000).

Ibu yang multipara memiliki proporsi yang lebih besar dalam memberikan ASI eksklusif dibandingkan ibu yang primipara. Ibu dengan jumlah persalinan lebih dari satu akan mengalami peningkatan jumlah produksi ASI. Soetjiningsih (1997) menyatakan pada kenaikan jumlah paritas ada sedikit perubahan produksi ASI, yaitu: (1) Anak pertama : jumlah ASI $+580 \mathrm{ml} / 24 \mathrm{jam}$, (2) Anak kedua : jumlah ASI $+654 \mathrm{ml} / 24 \mathrm{jam}$, (3) Anak ketiga : jumlah ASI $+602 \mathrm{ml} / 24 \mathrm{jam}$,
(4) Anak keempat : jumlah ASI $+600 \mathrm{ml} / 24 \mathrm{jam}$, (5) Anak kelima : jumlah ASI $+506 \mathrm{ml} / 24 \mathrm{jam}$, (6) Anak keenam : jumlah ASI $+524 \mathrm{ml} / 24 \mathrm{jam}$. Produksi ASI ibu yang melahirkan anak kembar juga akan mengalami peningkatan sehingga jumlah ASI akan mencukupi kebutuhan kedua anak. Pada ibu yang melahirkan lebih dari satu kali, produksi ASI pada hari keempat post partum jauh lebih tinggi dibandingkan ibu yang baru melahirkan pertama kali. (Proverawati dan Rahmawati, 2010). Hasil uji korelasi menunjukkan bahwa tidak terdapat hubungan antara paritas ibu dengan pemberian ASI eksklusif dengan nilai $\mathrm{p}=0,089$. Hal ini sesuai dengan penelitian sebelumnya yang dilakukan oleh Sathri (2010) dalam Dewi (2016) yang menunjukkan bahwa tidak terdapat hubungan antara paritas ibu dengan pemberian ASI eksklusif.

Penelitian sebelumnya yang dilakukan oleh Mabud, dkk. (2014) menyimpulkan bahwa ada hubungan antara paritas dengan pemberian ASI ekslusif. Semakin tinggi tingkat paritas ibu maka berpengaruh positif terhadap pemberian ASI eksklusif, karena jumlah anak mempengaruhi tingkat pengetahuan dan adanya pengalaman menyusui sebelumnya sehingga ibu yang mempunyai anak banyak akan memberikan ASI eksklusif. Sesuatu yang dialami seseorang akan menambah pengetahuan yang didapat. Pengalaman sebagai sumber pengetahuan adalah suatu cara untuk memperoleh kebenaran pengetahuan dengan cara mengulang kembali pengetahuan yang diperoleh dalam memecahkan masalah yang dihadapi di masa lalu. Kondisi ini menyebabkan, ibu yang multipara memiliki kemungkinan yang lebih besar untuk pemberian ASI eksklusif dibandingkan dengan ibu yang primipara.

Paritas saat ini tidaklah menjadi masalah bagi seorang ibu untuk memberikan ASI eksklusif. Dukungan dari petugas kesehatan, dukungan keluarga dan persiapan pada saat kehamilan dapat mempengaruhi pemberian ASI eksklusif. Ibu yang mempunyai anak $\geq 3$ memiliki lebih banyak waktu luang untuk datang ke fasilitas pusat kesehatan masyarakat. Ibu mempunyai kesempatan untuk memperoleh pengetahuan terkait dengan pemberian ASI eksklusif, sehingga informasi yang didapat terkait pemberian ASI dengan dipraktikkan. 
Kondisi ini akan mempengaruhi produksi ASI yang lebih banyak dan mencukupi kebutuhan bayi selama pemberian ASI eksklusif (Proverawati dan Rahmawati, 2010).

Berdasarkan hasil penelitian dapat diketahui bahwa mayoritas ibu melahirkan secara normal. Ibu yang melakukan persalinan normal memiliki proporsi yang lebih tinggi $(24,5 \%)$ dalam memberikan ASI eksklusif, dibandingkan ibu yang melakukan persalinan dengan tindakan operasi.

Penolong persalinan merupakan kunci utama keberhasilan pemberian menyusu dini dan pencegahan terhadap pemberian makanan prelakteal. Kunci pelaksanaan sepuluh langkah menyusui adalah dengan adanya komitmen penolong persalinan untuk melaksanakan Inisiasi Menyusui Dini (IMD) dan tidak memberikan apapun selain ASI kepada bayi baru lahir termasuk pemberian susu formula dan makanan ataupun minuman sebagai prelakteal (Rahardjo dan Setyowati, 2006).

Hasil uji korelasi menunjukkan bahwa tidak terdapat hubungan antara jenis persalinan dengan pemberian ASI eksklusif dengan nilai $\mathrm{p}=0,189$. Hasil penelitian ini sesuai dengan Agam dkk. (2009) yang juga menunjukkan bahwa tidak ada hubungan jenis persalinan dengan pemberian ASI eksklusif.

Penelitian menunjukkan bahwa ibu yang persalinannya normal maupun dengan tindakan operasi cenderung tidak memberikan ASI eksklusif. Pada persalinan normal, IMD tetap dilakukan, pemberian makanan prelakteal masih diberikan pada bayi. Ibu merasa ASI-nya belum keluar ataupun produksi ASI-nya kurang, sehingga penggunaan susu formula dan makanan prelakteal masih diberikan.

Rendahnya praktek menyusui pada ibu post sectio caesarea berhubungan dengan dukungan tenaga kesehatan. Hal ini dapat disebabkan oleh penolong persalinan yang kurang memberikan informasi tentang praktek inisiasi menyusui dini (IMD) dan pemberian ASI eksklusif sehingga ibu kurang memahami manfaat dan keuntungan ASI eksklusif (Wulandari dan Dewanti, 2014).

Ibu yang mendapatkan dukungan suami lebih besar peluangnya untuk memberikan ASI eksklusif dibandingkan dengan ibu yang tidak mendapatkan
Tabel 5. Hubungan Dukungan Suami dengan Pemberian ASI Esklusif

\begin{tabular}{lccccc}
\hline \multirow{2}{*}{$\begin{array}{c}\text { Dukungan } \\
\text { Suami }\end{array}$} & \multicolumn{4}{c}{ ASI Eksklusif } & \multirow{2}{*}{ p } \\
\cline { 2 - 5 } & \multicolumn{2}{c}{ Ya } & \multicolumn{2}{c}{ Tidak } & \\
\cline { 2 - 5 } & $\mathbf{n}$ & $\mathbf{\%}$ & $\mathbf{n}$ & $\mathbf{\%}$ & \\
\hline Mendukung & 13 & 27,1 & 35 & 72,9 & 0 \\
Tidak Mendukung & 1 & 5,6 & 17 & 94,4 & 0,058 \\
\hline
\end{tabular}

dukungan suami, meskipun secara statistik tidak terdapat hubungan yang signifikan antara dukungan suami dengan pemberian ASI eksklusif $(\mathrm{p}=0,058)$. Hasil penelitian ini sesuai dengan penelitian Dyan (2011).

Ayah dapat berperan lebih besar dalam mendukung pemberian ASI melalui dukungan dan bantuan lain seperti ikut membantu memandikan si bayi atau menggantikan popok. Peran ini merupakan langkah pertama bagi seorang ayah untuk mendukung keberhasilan ibu menyusui secara eksklusif. Membesarkan dan memberi makan anak adalah tugas bersama antara ayah dan ibu. Hubungan antara seorang ayah dan bayinya merupakan faktor yang penting dalam pertumbuhan dan perkembangan seorang anak. Ayah juga perlu mengerti dan memahami persoalan ASI dan menyusui agar ibu dapat menyusui dengan baik (Roesli, 2008).

Seorang suami yang mengerti dan memahami manfaat ASI pasti akan membantu ibu mengurus bayi, termasuk menggantikan popok, memandikan bayi, dan memberikan pijatan pada bayi. Sementara ibu, berusaha fokus meningkatkan kualitas ASI-nya dengan mengonsumsi makanan bergizi seimbang dan melakukan pola hidup sehat (Roesli, 2008).

Friedman dkk. (2003) menjelaskan bahwa dukungan suami memiliki empat fungsi yaitu dukungan informasional, dukungan penilaian, dukungan instrumental, dan dukungan emosional. Dukungan informasional adalah suami berfungsi sebagai penerima dan penyebar informasi tentang semua informasi yang ada dalam kehidupan. Suami mengingatkan dan memberitahukan ibu tentang informasi dalam pemberian ASI secara eksklusif. Sumber informasi dapat berasal dari tenaga kesehatan, media cetak dan lainnya. Dukungan penilaian adalah bentuk dukungan suami sebagai identitas anggota dalam status 
keluarga yang menjadi sumber validator dengan tegas pembimbing dan bimbingan umpan balik dalam memecahkan masalah.

Dukungan instrumental adalah bentuk dukungan suami sebagai penyediaan materi yang dapat memberikan pertolongan langsung seperti pemberian uang, pemberian barang, makanan serta pelayanan. Bentuk ini dapat mengurangi stress karena ibu dapat langsung memecahkan masalah yang berhubungan dengan materi. Dukungan emosional adalah bentuk dukungan keluarga ataupun suami sebagai sebuah tempat yang nyaman, aman dan damai. Membantu secara psikologis dalam menstabilkan emosi dan mengendalikan diri, maka dari itu bentuk dukungannya adalah dengan cara memberikan motivasi dan peranan dalam mendengarkan semua keluhan-keluhan masalah yang sedang dihadapinya (Friedman, 2003).

Dukungan suami berperan besar dalam keberhasilan ibu untuk memberikan ASI eksklusif. Semakin besar dukungan yang diberikan oleh suami maka semakin besar juga peluang ibu untuk menyusui bayinya. Hal ini akan mempengaruhi kelancaran refleks pengeluaran ASI, karena dipengaruhi oleh perasaan dan emosi ibu. Dukungan keluarga diperlukan untuk ketenangan, ketenteraman, dan kenyamanan ibu menyusui yang dapat meningkatkan produksi hormon oksitosin sehingga dapat meningkatkan pemberian ASI pada anak. Reeves, dkk. (2012) menyatakan bahwa ibu menyusui karena mereka percaya ASI lebih sehat untuk bayi. Suami merupakan pemberi dukungan yang paling berpengaruh. Sistem pendukung itu sangat penting bagi ibu menyusui untuk mengambil keputusan memberi ASI pada bayi umur $0-6$ bulan secara eksklusif. Hal ini mendukung penelitian yang dilakukan oleh Mazza, dkk. (2014), bahwa ada dua kategori yang berpengaruh dalam pemberian ASI, salah satunya adalah pengaruh sosial primer. Jaringan Primer ditandai oleh anggota keluarga dan orang-orang dekat. Suami dapat berperan dalam meningkatkan percaya diri ibu dalam memberikan ASI, kepercayaan diri ibu dapat meningkatkan produksi ASI.

Menurut Dirjen Gizi dan KIA, menyusui bayi umur 0-6 bulan secara eksklusif dipengaruhi oleh dukungan dari suami, keluarga, petugas kesehatan, masyarakat serta lingkungan kerja terhadap ibu menyusui (Kementerian Kesehatan RI, 2011). Pemberian ASI eksklusif pada bayi bukan hanya tanggung jawab ibu saja. Kepala keluarga, dalam hal ini suami juga memiliki tanggung jawab besar untuk memberikan dukungan (Pemprov DKI Jakarta, 2010).

Nasihat dari orang yang berpengalaman akan membantu keberhasilan menyusui (Nursalam, 2001). Rodrigues, et al (2013) menyatakan bila ibu yang mendapatkan dukungan dari anggota keluarga, terutama suami atau pasangan dan kakeknenek, berpengaruh positif terhadap kepercayaan diri terhadap menyusui. Anggota keluarga harus mendukung ibu dan membantu ibu dalam hal pemberian ASI sehingga ibu merasa mampu untuk menyusui.

\section{KESIMPULAN DAN SARAN}

Tidak terdapat hubungan signifikan antara dukungan suami dengan pemberian ASI eksklusif, namun proporsi ibu yang memberikan ASI eksklusif lebih tinggi pada ibu yang mendapatkan dukungan dari suami dibandingkan yang tidak mendapat dukungan dari suami.

Suami perlu memberikan dukungan pada istri dalam pemberian ASI eksklusif. Ibu menyusui perlu mendapatkan perhatian, pujian, ketenangan, kenyamanan, untuk menunjang keberhasilan pemberian ASI eksklusif. Perlu adanya pembentukan kelompok pendukung ASI (KP-ASI) Ayah Peduli ASI guna memberi dan menerima dukungan secara informasi, teknis, moral maupun emosional.

\section{DAFTAR PUSTAKA}

Agam, I., Syam, A., \& Citrakesumasari. (2009). Faktor-faktor yang mempengaruhi pemberian ASI eksklusif di Kelurahan Tamamaung Kecamatan Panakkukang Kota Makassar. Jurnal Ilmu Gizi Fakultas Kesehatan Masyarakat, 1, $1-9$.

Ariani. (2010). Ibu susui aku, bayi sehat dan cerdas dengan ASI. Bandung: Khasanah Intelektual.

Arini, H. (2012). Mengapa seorang ibu harus menyusui. Yogyakarta: FlashBooks.

Ahmad, A. (2014). Faktor ibu yang berhubungan 
dengan praktik pemberian ASI eksklusif di wilayah kerja Puskesmas Pamotan. Jurnal Ilmu Kesehatan Masyarakat, 3(1), 1-8.

Depkes. (2001). Strategi nasional peningkatan pemberian ASI (PP-ASI). Jakarta : Departemen Kesehatan Republik Indonesia.

Dewi, U.M. (2016). Faktor yang mempengaruhi praktik menyusui pada ibu post sectio caesarea di RSI A. Yani Surabaya. Jurnal Ilmiah Kesehatan, 9(1), 43-47.

Friedman, M, Bowden, V.R., \& Jones, E.G. (2003). Family nursing research, theory and practice. New Jersey: Prentice Hall.

Febriyanti, R. \& Ernawati, D.(2014). Analisis faktorfaktor yang mempengaruhi pemberian ASI eksklusif di Desa Gilang Taman Sidoarjo. Jurnal Ilmiah Keperawatan Stikes Hang Tuah Surabaya, 6. Diakses dari file://C:/Users/Fitri\%20 Amalia/Downloads/MANUSKRIP $\% 20$ ROSALINA\%20(SECURE)\%20(5).pdf.

Ibrahim. (2000). Hubungan sikap ibu dengan pemberian asi eksklusif di wilayah kerja Puskesmas Cot Weh pada bayi (0-11 bulan) di Kabupaten Aceh Besar Propinsi Daerah Istimewa Aceh (Tesis tidak dipublikasikan). Universitas Sumatera Utara, Medan.

Mabud, N.H., Mandang, J., \& Mamuaya, T. (2014). Hubungan pengetahuan, pendidikan, paritas, dengan pemberian ASI eksklusif di Puskesmas Bahu Kecamatan Malalayang Kota Manado. Jurnal Ilmiah Bidan. 2(2), 51-56.

Mazza, V.D.A., Regina, C.T.N., \& Rafaela, Z.P.T. (2014). Influence of social support networks for adolescent breastfeeding mother in the process of breastfeeding. International Breastfeeding Journal, 19, 1-7.

Kementerian Kesehatan RI. (2013). Profil kesehatan Indonesia 2012. Jakarta: Kementerian Kesehatan RI.

Kementerian Kesehatan RI. (2011). Banyak sekali manfaat asi bagi bayi dan ibu. Diakses dari http://www.depkes.go.id/article/print/1450/ banyak-sekali-manfaat-asi-bagi-bayi-dan-ibu--. html.
Notoatmodjo, S. (2003). Pendidikan dan perilaku kesehatan. Jakarta: Rineka Cipta

Notoatmodjo, S. (2005). Pendidikan dan perilaku kesehatan. Jakarta: Rineka Cipta.

Notoatmodjo, S. (2007). Pendidikan dan perilaku kesehatan. Jakarta: Rineka Cipta.

Nursalam. (2001). Metodologi riset keperawatan. Jakarta: Infomedika.

Pemprov DKI Jakarta. (2010). Pemberian ASI eksklusif perlu ditingkatkan. Diakses dari http:// www.beritajakarta.com/2008/id/berita.

Proverawati, A., \& Rahmawati, E. (2010). Kapita selekta ASI dan menyusui. Yogyakarta: Nuha Medika.

Rahardjo \& Setyowati. (2006). Faktor-faktor yang berhubungan dengan pemberian ASI satu jam pertama setelah melahirkan. Jurnal Kesehatan Masyarakat Nasional, 1, 11-17.

Reeves, C., Close, F.T., Simmons, M.C., \& Hollis, A.L. (2012). Social support indicators that influence breastfeeding decision in mothers of north florida. Florida Public Health Review, 3, 1-7.

Rodrigues A P, Padoin S M, Demello, Depaula C C, $\&$ Guido D A. (2013). Factors those influence in self efficacy of breastfeeding. International Breastfeeding Journal, 7(5), 1-10.

Roesli. (2000). Mengenal ASI ekslusif. Jakarta: Pustaka Pengembangan Swadaya Nusantara.

Roesli, U. (2008). Mengenal ASI ekslusif. Jakarta: Pustaka Bunda.

Roesli, U. (2012). Inisiasi menyusui dini plus ASI eksklusif. Jakarta: Pustaka Bunda (Grup Puspa Swara).

Soetjiningsih. (1997). Petunjuk untuk tenaga kesehatan. Jakarta: EGC.

WHO, UNICEF. 2003. Exclusive breastfeeding. Diakses dari http://www.who.int/elena/titles/ exclusive_breastfeeding/en/.

Wulandari, D.R., \& Dewanti, L. 2014. Rendahnya praktik menyusui pada ibu post sectio caesaria dan dukungan tenaga kesehatan di rumah sakit. Jurnal Kesehatan Masyarakat, 8(8): 393-397.

Yuliarti, N. (2010). Makanan terbaik untuk kesehatan, kecerdasan, dan kelincahan si kecil. Yogyakarta: Andi. 